\title{
Studi Ruang Lingkup K3 Rumah Sakit Dalam Proses Implementasi Keperawatan
}

\section{Emyranda Samosir}

emyrandasamosir@gmail.com

\begin{abstract}
Proses keperawatan adalah metode dimana suatu konsep diterapkan dalam praktik keperawatan. Hal ini bisa disebut sebagai suatu pendekatan problem-solving yang memerlukan ilmu, teknik, dan ketrampilan interpersonal dan ditujukan untuk memenuhi kebutuhan klien/ keluarga. Proses keperawatan terdiri dari lima tahap yang sequensial dan berhubungan. Antara lain yaitu pengkajian, diagnosis, perencanaan, pelaksanaan, dan evaluasi. Tahap tersebut berintegrasi dalam mendefinisikan suatu tindakan perawatan. Salah satunya adalah implementasi atau pelaksanaan.Dalam asuhan keperawatn sering kali dijumpai kesalahan-kesalahan khususnya pada saat implementasi keperawatan berlangsung tak jarang pula kesalahan tersebut menyerang perawat,pasien bahkan keluarga.Hal ini dikarenakan kurangnya pengetahuan dan kesadaran diri perawat akan kebijakan, ruang lingkup,tujuan,manfat dan etika K3 RS bagi perawat. Saat ini perawat memiliki peran yang lebih luas dengan penekanan pada peningkatan kesehatan dan pencegahan penyakit, juga memandang klien secara komprehensif. Perawat menjalankan fungsi dalam kaitannya dengan berbagai peran pemberi perawatan, pembuat keputusan klinik dan etika, pelindung dan advokat bagi klien, manajer kasus, rehabilitator, komunikator dan pendidik
\end{abstract}

Kata Kunci : Kebijakan K3 dalam Keperawatan,Ruang lingkup K3,Manfaat K3,Tujuan K3, Implementasi Keperawatan 


\section{Latar Belakang}

Keperawatan digunakan secara terusmenerus ketika merencanakan dan memberikan asuhan keperawatan dengan mempertimbangkan pasien sebagai figur central dalam merencanakan asuhan dengan mengobservasi respons pasien terhadap setiap tindakan sebagai penatalaksanaan dalam suatu asuhan keperawatan.Pada saat implementasi perawat harus melaksanakan hasil dari rencana keperawatan yang di lihat dari diagnosa keperawatan. Tujuan dari pelaksanaan adalah membantu klien dalam mencapai tujuan yang telah ditetapkan, yang mencakup peningkatan kesehatan, pencegahan, penyakit, pemulihan kesehatan dan memfasilitasi koping.

\section{Kesehatan dan Keselamatan Kerja} (K3) merupakan suatu upaya perlindungan kepada tenaga kerja dan orang lain yang memasuki tempat kerja terhadap bahaya dari akibat kecelakaan kerja. Tujuan K3 adalah mencegah, mengurangi resiko penyakit dan kecelakaan akibat kerja (KAK) serta meningkatkan derajat Kesehatan para pekerja sehingga produktivitas kerja meningkat derajat kesehatan para pekerja sehingga produktivitas kerja meningkat. Pelayanan Kesehatan dirumah sakit merupakan pemenuhan kebutuhan dan tuntutan dari pemakai jasa pelaayanan atau pasien yang mengharapkan penyembuhan dan pemulihan yang berkualitas dan penyediaan pelayanan kesehatan yang nyaman dan aman.

Agar dapat mewujudkan tercapainya pelayanan yang berkualitas dan berkinerja tinggi diperlukan tenaga keperawatan yang profesional, memiliki kemampuan intelektual, teknikal dan interpersonal, bekerja berdasarkan standar praktik, memperhatikan kaidah etik dan moral.Pelayanan keperawatan yang berkualitas sangat dipengaruhi oleh faktor balas jasa yang adil dan layak, kemampuan yang cakap dan profesional, penempatan yang tepat sesuai keahliannya, berat ringannya pekerjaan atau beban kerja perawat sifat pekerjaan, suasana dan lingkungan pekerjaan, peralatan yang menunjang, serta sikap pimpinan dalam memberikan bimbingan dan pembinaan. Mutu pelayanan perawat sangat dipengaruhi oleh lingkungan pekerjaannya, penghargaan yang didapatkan, bahkan diberikan sanksi bila terjadi kesalahan. Beban kerja tinggi dapat menyebabkan ketelitian dan keamanan kerja menjadi turun, sehingga mutu dan kinerja mereka juga cenderung menurun. 


\section{Tujuan}

\begin{abstract}
Tujuandari pelaksanaan /
implementasi adalah membantu klien dalam mencapai tujuan yang telah ditetapkan, yang mencakup peningkatan kesehatan, pencegahan, penyakit, pemulihan kesehatan dan memfasilitasi koping. Melaksanakan hasil dari rencana keperawatan untuk selanjutnya di evaluasi untukmengetahui kondisi kesehatan pasien dalam periode yang singkat, untuk mempertahankan daya tahan tubuh, untuk mencegah komplikasi, untuk menemukan perubahan system tubuh, untuk memberikan lingkungan yang nyaman bagi klien, dan untuk mengimplementasi pesan dokter.
\end{abstract}

Tujuan dari keselamatan pasien ialah :

1. Terciptanya budaya keselamatan pasien di rumah sakit

2. Meningkatnya Akuntabilitas rumah sakit terhadap pasien

3. Menurunnya KTD di Rumah Sakit

4. Terlaksananya program-program pencegahan sehingga tidak terjadi penggulangan KTD

Tujuan dari kajian ini ialah mengetahui kebijakan K3 yang berkaitan dengan keperawatan,Ruang lingkup ,manfaat ,tujuan serta pentingnya K3 dalam Keperawatan .

\section{Metode}

Rancangan penugasan kajian ini menggunakan literature review berdasarkan buku teks, buku referensi, jurnal, e-book (yang dipublikasikan 10 tahun terakhir) dan menggunakan dua belas sumber referensi dengan menganalisis, eksplorasi, dan kajian bebas sesuai dengan judul penugasan kajian ini

\section{Hasil}

Implementasi sebagai salah satu Langkah dari asuhan keperawatan tidak dapat dianggap sebagai Langkah yang sepele.Sebelum melakukan implementasi perawat harus memastika, tujuan,dampak,ruang lingkup,peranan serta etika yang akan perawat laksanakan dalam proses implemetasi yang tujuannya agar pasien dapat memperoleh pemulihan secara maksimal.Tak terkecuali pada keselamatan dan Kesehatan kerja rumah sakit saat proses implemetasi.Hal ini tidak terlepas dari tujuan dari K3 yaitu Agar perawat dan setiap orang berada di tempat kerja selalu dalam keadaan sehat dan selamat. Agar implemetasi keperawatan dapat berjalan secara lancar tanpa adanya hambatan. Ruang lingkup kerja perawat dalam proses implemetasi meliputi : 
- Kesehatan dan keselamatan kerja diterapkan di semua tempat kerja yang di dalamnya melibatkan aspek manusia sebagai tenaga kerja, bahaya akibat kerja dan usaha yang dikerjakan.

- Aspek perlindungan dalam hyperkes meliputi :

1) Tenaga kerja dari semua jenis dan jenjang keahlian

2) Peralatan dan bahan yang dipergunakan

3) Faktor-faktor lingkungan fisik, biologi, kimiawi, maupun sosial.

4) Proses produksi

5) Karakteristik dan sifat pekerjaan

6) Teknologi dan metodologi kerja

Adapun Relevansi kebijakan K3 Nasional dengan tugas perawat:

$\checkmark$ Pemberi asuhan keperawatan

$\checkmark$ Penyuluh dan konselor bagi klien

$\checkmark$ Pengelola pelayanan keperawatan

$\checkmark$ Peneliti keperawatan

$\checkmark$ Pelaksanaan tugas berdasarkan pelimpahan wewenang

$\checkmark$ Pelaksanaan tugas dalam keterbatasan tertentu

\section{Pembahasan}

Proses keperawatan menyediakan struktur bagian praktis dengan penggunaan pengetahuan dan keterampilan yang dilakukan oleh perawat untuk mengekspresikankebutuhan perawatan (human caring). Keperawatan digunakan secara terus-menerus ketika merencanakan dan memberikan asuhan keperawatan dengan mempertimbangkan pasien sebagai figur central dalam merencanakan asuhan dengan mengobservasi respons pasien terhadap setiap tindakan sebagai penatalaksanaan dalam suatu asuhan keperawatan.Pada saat implementasi perawat harus melaksanakan hasil dari rencana keperawatan yang di lihat dari diagnosa keperawatan. Di mana perawat membantu klien dari masalah status kesehatan yang dihadapi kestatus kesehatan yang lebih baik yang menggambarkan kriteria hasil yang diharapkan. Implementasi keperawatan adalah serangkaian kegiatan yang dilakukan oleh perawat untuk membantu klien dari masalah status kesehatan yang dihadapi kestatus kesehatan yang lebih baik yang menggambarkan kriteria hasil yang diharapkan. Implementasi merupakan inisiatif dari rencana tindakan untuk mencapai tujuan yang spesifik. Tahap pelaksanaan dimulai setelah rencana tindakan disusun dan ditujukan pada nursing orders untuk membantu klien mencapai tujuan yang diharapkan. Oleh karena itu rencana tindakan yang spesifik dilaksanakan 
untuk memodifikasi faktor-faktor yang mempengaruhi masalah kesehatan klien.

Rumah sakit sebagai salah satu fasilitas pelayanan kesehatan dapat menjadi tempat yang berbahaya dan berisiko tinggi untuk keselamatan kerja. Tenaga keperawatan yang bekerja secara berkesinambungan memberikan pelayanan keperawatan di rumah sakit secara terus menerus selama 24 jam setiap hari berisiko mengalami penyakit dan kecelakaan kerja. Setiap tenaga kerja yang bertugas di pelayanan kesehatan termasuk perawat berhak atas perlindungan dan keselamatannya dalam melakukan pekerjaannya. Perawat dalam memberikan asuhan keperawatan memiliki hak untuk bekerja dengan aman sehingga dapat memberikan pelayanan yang berkualitas kepada pasien (American Nurses Association, 2007).

Kecelakanaan kerja dapat diakibatkan karena rendahnya pengetahuan pekerja tentang suatu teknik keselamatan dan kesehatan kerja di lingkungan kerja. Beberapa faktor yang dapat berpengaruh yaitu faktor pendidikan, pekerjaan, umur, lingkungan, dan social. Hal itu dikarenakan faktor tersebut dapat mempengaruhi pengetahuan seseorang tentang suatu objek atau subjek (A. Wawan dkk., 2011).
Ruang lingkup k3 (Rachman, 1990) :

A. Kesehatan dan keselamatan kerja diterapkan di semua tempat kerja yang di dalamnya melibatkan aspek manusia sebagai tenaga kerja, bahaya akibat kerja dan usaha yang dikerjakan.

B. Aspek perlindungan dalam hyperkes meliputi :

1) Tenaga kerja dari semua jenis dan jenjang keahlian

2) Peralatan dan bahan yang dipergunakan

3) Faktor-faktor lingkungan fisik, biologi, kimiawi, maupun sosial.

4) Proses produksi

5) Karakteristik dan sifat pekerjaan

6) Teknologi dan metodologi kerja

C. Penerapan Hyperkes dilaksanakan secara holistik sejak perencanaan hingga perolehan hasil dari kegiatan industri barang maupun jasa

D. Semua pihak yang terlibat dalam proses industri/ perusahaan ikut bertanggung jawab atas keberhasilan usaha hyperkes.

Kebijakan K3 yang berkaitan dengan keperawatan di Indonesia.Relevansi kebijakan K3 Nasional dengan tugas perawat: 
$\checkmark$ Pemberi asuhan keperawatan

$\checkmark$ Penyuluh dan konselor bagi klien

$\checkmark$ Pengelola pelayanan keperawatan

$\checkmark$ Peneliti keperawatan

$\checkmark$ Pelaksanaan tugas berdasarkan pelimpahan wewenang

$\checkmark$ Pelaksanaan tugas dalam keterbatasan tertentu

Fungsi seorang perawat hiperkes sangat tergantung kepada kebijaksanaan perusahaan dalam hal luasnya ruang lingkup usaha kesehatan, susunan dan jumlah tenaga kesehatan yang dipekerjakan dalam perusahaan.

Perawat merupakan satu-satunya tenaga kesehatan yang full time di perusahaan, maka fungsinya

$$
\text { adalah }
$$

1. Membantu dokter perusahaan dalam menyusun rencana kerja hiperkes di perusahaan

2. Melaksanakan program kerja yang telah digariskan, termasuk administrasi kesehatan kerja.

3. Memelihara dan mempertinggi mutu pelayanan perawatan dan pengobatan. 4. Memelihara alat-alat perawatan, obatobatan dan fasilitas kesehatan perusahaan.

5. Membantu dokter dalam pemeriksaan kesehatan sesuai cara-cara yang telah disetujui.

6. Ikut membantu menentukan kasus-kasus penderita, serta berusaha menindaklanjuti sesuai wewenang yang diberikan kepadanya. 7. Ikut menilai keadaan kesehatan tenaga kerja dihubungkan dengan faktor pekerjaan dan melaporkan kepada dokter perusahaan. 8. Membantu usaha perbaikan kesehatan lingkungan dan perusahaan sesuai kemampuan yang ada.

9. Ikut mengambil peranan dalam usahausaha kemasyarakatan : UKS. 10. Membantu, merencanakan dan atau melaksanakan sendiri kunjungan rumah sebagai salah satu dari segi kegiatannya. 11. Menyelenggarakan pendidikan hiperkes kepada tenaga kerja yang dilayani. 12. Turut ambil bagian dalam usaha keselamatan kerja. 13. Mengumpulkan data-data dan membuat laporan untuk statistic dan evaluasi. 14. Turut membantu dalam usaha penyelidikan kesehatan tenaga kerja. 15. Memelihara hubungan yang harmonis dalam

perusahaan 16. Memberikan penyuluhan dalam bidang kesehatan

17. Bila lebih dari satu paramedis hiperkes dalam satu perusahaan, maka pimpinan paramedis hiperkes harus mengkoordinasi dan mengawasi pelaksanaan semua usaha perawatan hiperkes. Menurut Jane A. Le R.N dalam bukunya The 
New Nurse in Industry, beberapa fungsi specific dari perawat hiperkes adalah : 1. Persetujuan dan kerjasama dari pimpinan perusahaan/ industry dalam membuat program dan pengolahan pelayanan hiperkes yang mana bertujuan memberikan pemeliharaan / perawatan kesehatan yang sebaik mungkin kepada tenaga kerja 2. Memberikan/ menyediakan primary nursing care untuk penyakit -penyakit atau korban kecelakaan baik akibat kerja maupun yang bukan akibat kerja bedasarkan petunjuk- petunjuk kesehatan yang ada. 3. Mengawasi pengangkutan si sakit korban kecelakaan ke rumah sakit, klinik atau ke kantor dokter untuk mendapatkan perawatan / pengobatan lebih lanjut 4. Melakukan referral kesehatan dan pencanaan kelanjutan perawatan dan follow up dengan rumah sakit atau klinik spesialis yang ada

5. Mengembangkan dan memelihara system record dan report kesehatan dan keselamatan yang sesuai dengan prosedur yang ada di perusahaan

6. Mengembangkan dan memperbarui policy dan prosedur servis perawatan 7. Membantu program physical examination (pemeriksaan fisik) dapatkan data-data keterangan-keterangan mengenai kesehatan dan pekerjaan. Lakukan referral yang tepat dan berikan suatu rekomendasi mengenai hasil yang positif.

8. Memberi nasehat pada tenaga kerja yang mendapat kesukaran dan jadilaj perantara untuk membantu menyelesaikan persoalan baik emosional maupun personal. 9. Mengajar karyawan praktek kesehatan keselamatan kerja yang baik,dan memberikan motivasi untuk memperbaiki praktek-praktek kesehatan. 10. Mengenai kebutuhan kesehatan yang diperlukan karyawan dengan obyektif dan menetapkan program Health Promotion, Maintenance and Restoration 11. Kerjasama dengan tim hiperkes atau kesehatan kerja dalam mencari jalan bagaimana untuk peningkatan pengawasan terhadap lingkungan kerja dan pengawasan kesehatan yang terus menerus terhadap karyawan yang terpapar dengan bahan-bahan yang dapat membahayakan kesehatannya. 12. Tetap waspada dan mengikuti standarstandar kesehatan dan keselamatan kerja yang ada dalam menjalankan praktek-praktek perawatan dan pengobatan dalam bidang hiperkes ini. 13. Secara periodic untuk meninjau kembali program-program perawatan dan aktifitas perawatan lainnya demi untuk kelayakan dan memenuhi kebutuhan serta efisiensi. 14. Ikut serta dalam organisasi perawat 
(professional perawat) seperti ikatan paramedic hiperkes, dan sebagainya. 15. Merupakan tanggung jawab pribadi yang tidak boleh dilupakan dan penting adalah mengikuti kemajuan dan perkembangan professional (continues education)

\section{Penutup}

Sebelum memberikan implementasi keperawatan,perawat harus mengetahui dan menggerti menggenai ruang lingkup,kebijakan,serta etika yang terkait terhadap implementasi keperawatan yang akan dilaksanakan,salah satunya ialah keselamatan dan Kesehatan kerja di rumah sakit . Ruang Lingkup K3 dalam proses Implementasi keperawatan ialah Keterlibatan perawat sebagai aspek manusia sebagai tenaga kerja, bahaya akibat kerja dan usaha yang dikerjakan selam proses implementasi.Tujuan dari K3 dalam proses implementasi ialah . Agar perawat dan setiap orang berada di tempat kerja selalu dalam keadaan sehat dan selamat. Agar implemetasi keperawatan dapat berjalan secara lancar tanpa adanya hambatan.

\section{Daftar Pustaka}

Handayani,S.et.al..(2017).

Evaluasi Penerapan Pencegahan

Pasien Berisiko Jatuh di Rumah Sakit.Jurnal Fakultas Ilmu Keperawatan Universitas

Padjajaran.2(3).6-10.

Handayani,L.T (2017).

Analisis Jalur Keselamatan Dan

Kesehatan Kerja Dengan Kepuasan

Terhadap Kinerja Perawat Dalam

Memberikan Asuhan Keperawatan

Di Rs Di Jember. THE INDONESIAN

JOURNAL OF HEALTH SCIENCE.9

(1).44-47

Ivana,A.(2014).

Analisa Komitmen Manajemen

Rumah Sakit (RS) Terhadap

Keselamatan DanKesehatan Kerja

(K3) Pada RS Prima Medika

Pemalang.Journal Kesehatan

Masyarakat.2(1).37

Kamil,H.(2017).

PATIENT SAFETY. Idea Nursing Journal Hajjul Kamil.1(1).4-7 
Simamora, R. H. (2018).

Maharani,D.P.(2017).

Pengetahuan,Sikap,dan Kebijakan K3 dengan Penggunaa Alat Pelindung Diri di bagian Ring Spinning Unit 1.Journal Of Health education.2(1).34-35

Nazira,\&Yuswardi.(2017).

Perilaku Perawat Dalam Penerapan Manajemen Kesehatan Dan Keselamatan Kerja (K3) Di Aceh.Idea Nursing Journa.8(3).2526

Piri, Sovian. (2015).

Pengaruh Kesehatan,

Pelatihan dan Penggunaan Alat

Pelindung Diri terhadap Kecelakaan

Kerja pada pekerja Konstruksi di Kota Tomohon.Jurnal Ilmiah Media

Engineering.2(4) .66
Buku ajar keselamatan pasien melalui timbang terima pasien berbasis komunikasi efektif: SBAR. Medan: USUpress.

Simamora, R. H. (2019).

Buku ajar pelaksanaan identifikasi pasien. Uwais Inspirasi Indonesia.
Trisnantoro, et.al (2012).

Kebijakan Keperawatan Berbasis Kinerja Di Rsu Tangerang. JURNAL MANAJEMEN PELAYANAN KESEHATAN.15(1).16-17

Tukatman.,Sulistiawati.et.al.(2015). Analisis Keselamatan Dan Kesehatan Kerja Perawat Dalam Penanganan Pasien Di Rumah Sakit Benyamin Guluh Kabupaten Kolaka. Jurnal Ners 10(2).66-68

Ramdan,I.\& Rahman.(2017).

Analisis Risiko Kesehatan dan Keselamatan Kerja (K3)pada Perawat.JKP.5(3).230-234 